\title{
Intravenous 5-fluoro-2'-deoxycytidine administered with tetrahydrouridine increases the proportion of p16-expressing circulating tumor cells in patients with advanced solid tumors
}

\author{
Geraldine O.'Sullivan Coyne ${ }^{1} \cdot$ Lihua Wang $^{2} \cdot$ Jennifer Zlott ${ }^{1} \cdot$ Lamin Juwara $^{3}$. Joseph M. Covey ${ }^{1} \cdot$ Jan H. Beumer ${ }^{4}$. \\ Mihaela C. Cristea ${ }^{5}$ Edward M. Newman ${ }^{5}$. Stephen Koehler ${ }^{6}$. Jorge J. Nieva ${ }^{7}$ Agustin A. Garcia ${ }^{7,10}$. \\ David R. Gandara ${ }^{8}$ - Brandon Miller ${ }^{2}$. Sonny Khin ${ }^{2}$. Sarah B. Miller ${ }^{1}$. Seth M. Steinberg ${ }^{9}$ - Larry Rubinstein ${ }^{1}$. \\ Ralph E. Parchment ${ }^{2} \cdot$ Robert J. Kinders $^{2} \cdot$ Richard L. Piekarz $^{1} \cdot$ Shivaani Kummar $^{1} \cdot$ Alice P. Chen $^{1}$. \\ James H. Doroshow ${ }^{1,9}$
}

Received: 9 December 2019 / Accepted: 6 April 2020 / Published online: 20 April 2020

(c) The Author(s) 2020

\begin{abstract}
Purpose Following promising responses to the DNA methyltransferase (DNMT) inhibitor 5-fluoro-2'-deoxycytidine (FdCyd) combined with tetrahydrouridine (THU) in phase 1 testing, we initiated a non-randomized phase 2 study to assess response to this combination in patients with advanced solid tumor types for which tumor suppressor gene methylation is potentially prognostic. To obtain pharmacodynamic evidence for DNMT inhibition by FdCyd, we developed a novel method for detecting expression of tumor suppressor protein p16/INK4A in circulating tumor cells (CTCs).

Methods Patients in histology-specific strata (breast, head and neck [H\&N], or non-small cell lung cancers [NSCLC] or urothelial transitional cell carcinoma) were administered FdCyd $\left(100 \mathrm{mg} / \mathrm{m}^{2}\right)$ and THU $\left(350 \mathrm{mg} / \mathrm{m}^{2}\right)$ intravenously 5 days/ week for 2 weeks, in 28-day cycles, and progression-free survival (PFS) rate and objective response rate (ORR) were evaluated. Blood specimens were collected for CTC analysis.

Results Ninety-three eligible patients were enrolled ( 29 breast, 21 H\&N, 25 NSCLC, and 18 urothelial). There were three partial responses. All strata were terminated early due to insufficient responses (H\&N, NSCLC) or slow accrual (breast, urothelial). However, the preliminary 4-month PFS rate (42\%) in the urothelial stratum exceeded the predefined goal-though the ORR (5.6\%) did not. An increase in the proportion of p16-expressing cytokeratin-positive CTCs was detected in 69\% of patients evaluable for clinical and CTC response, but was not significantly associated with clinical response.

Conclusion Further study of FdCyd + THU is potentially warranted in urothelial carcinoma but not NSCLC or breast or $\mathrm{H} \& \mathrm{~N}$ cancer. Increase in the proportion of p16-expressing cytokeratin-positive CTCs is a pharmacodynamic marker of FdCyd target engagement.
\end{abstract}

Keywords DNMT1 inhibitors $\cdot$ Cancer epigenetics $\cdot$ Epigenetic modifying agents $\cdot$ Circulating tumor cells $\cdot$ p16

Geraldine O.'Sullivan Coyne, Lihua Wang have contributed equally to this work.

Electronic supplementary material The online version of this article (https://doi.org/10.1007/s00280-020-04073-5) contains supplementary material, which is available to authorized users.

James H. Doroshow

doroshoj@mail.nih.gov

Extended author information available on the last page of the article

\section{Introduction}

Many malignancies are characterized by DNA methylationmediated silencing of tumor suppressor gene expression. DNA methyltransferase (DNMT) enzymes catalyze the addition of a methyl group at the 5 position of cytosine residues found within $\mathrm{CpG}$ dinucleotide-rich islands throughout the genome, and frequent overexpression of DNMTs in tumor cells yields increased methylation of $\mathrm{CpG}$ islands within promoters and other regulatory regions [1]. This hypermethylation recruits proteins involved in heterochromatin formation, leading to transcriptional repression. Genes found in 
transcriptionally repressed regions within cancer cell nuclei include those encoding proteins involved in the regulation of cell cycle progression, DNA repair, apoptosis, and drug metabolism - such as the cyclin-dependent kinase (CDK) 4/6 inhibitor p16/INK4A (encoded by CDKN2A), von Hippel Lindau tumor suppressor gene $(V H L)$, retinoblastoma 1 $(R B 1)$, and MutL protein homologue 1 (MHL1) [1, 2].

$C D K N 2 A$ is one of the most frequently methylated genes across common cancer types and is often differentially silenced in primary tumors and tumor cell lines relative to non-malignant cells [2]. CDKN2A methylation and/or p16 expression has been shown to have prognostic value in nonsmall cell lung cancer (NSCLC), bladder cancer, and head and neck $(H \& N)$ cancers [3-6]. The potential of p16 as a pharmacodynamic (PD) biomarker for DNMT inhibitors has also been demonstrated, with treatment-induced increases in p16 expression observed in patient tumors from a phase 1 trial of decitabine in lung and esophageal cancers [7]. Thus, p16 expression represents a promising approach for monitoring the PD effects of DNMT inhibition.

Two DNA hypomethylating agents, 5-aza-2'deoxycytidine (decitabine) and 5-azacytidine (azacytidine), are FDAapproved for treatment of specific forms of acute myeloid leukemia, chronic myelomonocytic leukemia, and myelodysplastic syndromes-with response rates of approximately 50\% across these diseases [8]. In contrast, monotherapy studies with demethylating agents in patients with advanced solid tumors have yielded only modest clinical activity and substantial toxicity, presumably due to cytotoxic nucleoside analog metabolites [9].

FdCyd, or 5-fluoro-2'-deoxycytidine, is a fluoropyrimidine nucleoside analog that, as has been demonstrated in vitro, is tri-phosphorylated and subsequently incorporated into DNA, where it covalently binds DNMT to inhibit DNA methylation $[10,11]$. Unlike decitabine and azacytidine, FdCyd is stable in aqueous solution. However, like other cytidine analogs, FdCyd is rapidly metabolized in vitro and in humans and other animals by cytidine deaminase, forming the cytotoxic DNA replication inhibitor 5-fluoro2'-deoxyuridine (FdUrd) [12-14]. Co-administration with the cytidine deaminase inhibitor tetrahydrouridine (THU) has been shown to increase in vivo FdCyd antitumor activity [14] and exposure [12,13], attenuating levels of the cytotoxic FdUrd metabolite.

In our phase 1 study of FdCyd combined with THU, the combination was well tolerated and elicited a partial response (PR) that was sustained for 16 months in a patient with refractory breast cancer [15]. Therefore, we conducted a multicenter phase 2 study to determine the objective response rate (ORR) and progression-free survival (PFS) for FdCyd + THU in 4 strata-each specific to a cancer type for which there was clinical or preclinical evidence that tumor suppressor gene methylation may be associated with prognosis: breast $[16,17]$, head and neck $[18,19]$, and nonsmall cell lung $[3,5,20]$ cancers and urothelial transitional cell carcinoma $[6,21,22]$. In addition to the main objectives of determining ORR and PFS, we also assessed toxicity, pharmacokinetics (PK), and PD responses to this regimen.

Given the extended timeframe of molecular response to epigenetic-modulating agents, we performed longitudinal PD assessments using liquid biopsies in this phase 2 study. Pharmacodynamic measurements in circulating tumor cells (CTCs) enabled PD response monitoring at multiple time points throughout treatment. FdCyd target engagement was assessed by measuring downstream expression of p16 in CTCs isolated from blood specimens using the FDA-cleared 4-channel CellSearch ${ }^{\circledR}$ system, which utilizes EpCAM and CD146 capture beads [23]. Initially, we focused this analysis on epithelial-phenotype (cytokeratin-positive, putatively EpCAM-expressing) CTCs. However, during the course of the trial, new knowledge came to light regarding the biological relevance and potential prognostic value of mesenchymal- and mixed epithelial/mesenchymal (E/M)-phenotype CTCs in patients with metastatic disease [24-27]. Therefore, we developed and validated a novel 5-channel CellSearch ${ }^{\circledR}$ assay to assess treatment-induced changes in p16 expression in the putative mixed E/M-phenotype (vimentin-positive, putatively EpCAM-expressing) CTC subpopulation for patients who enrolled during the final years of the study, after validation of this assay for E/M-phenotype CTCs had been completed. On this laboratory-specific platform, CTCs were identified as $\mathrm{MUC1}^{+} / \mathrm{CD}^{2} 5^{-}$.

\section{Materials and methods}

\section{Eligibility criteria}

Patients age 18 years and older with histologically confirmed breast cancer, NSCLC, H\&N cancer, or urothelial transitional cell carcinoma whose disease had progressed after at least one line of standard therapy were enrolled. Patients were required to have a Karnofsky performance status of $\geq 60 \%$ and adequate organ and marrow function, as defined by platelet count $\geq 100,000 / \mu \mathrm{L}$, absolute neutrophil count $\geq 1500 / \mu \mathrm{L}$, total bilirubin $<1.5 \times$ the institutional upper limit of normal (ULN), alanine aminotransferase and/ or aspartate aminotransferase $\leq 3 \times \mathrm{ULN}$ (or, for patients with liver metastases, $\leq 5 \times \mathrm{ULN}$ ), and creatinine $<1.5 \times \mathrm{ULN}$ (or, 
for patients with levels $>1.5 \times \mathrm{ULN}$, creatinine clearance of $\geq 60 \mathrm{~mL} / \mathrm{min}$ ). Patients were required to have completed any prior therapies $\geq 4$ weeks prior to enrollment and must have recovered to eligibility levels for performance status and organ function following any prior toxicities.

\section{Trial design}

This multicenter study (ClinicalTrials.gov identifier: NCT00978250) was conducted under an NCI-held investigational new drug application, with institutional review board approval at each participating site. This study was comprised of 4 strata based on tumor type: breast cancer, NSCLC, $\mathrm{H} \& \mathrm{~N}$ cancer, and urothelial transitional cell carcinoma.

FdCyd and THU were supplied by the NCI Division of Cancer Treatment of Diagnosis. Patients were administered the recommended phase 2 doses and schedules: FdCyd $\left(100 \mathrm{mg} / \mathrm{m}^{2} /\right.$ day) by 3 -h intravenous infusion in $5 \%$ dextrose, and THU $\left(350 \mathrm{mg} / \mathrm{m}^{2} /\right.$ day) in part as a bolus ( $20 \%$ of the daily dose), with the remaining co-administered with FdCyd over 3-h infusion on days $1-5$ and $8-12$ of each 28-day cycle. Patients maintained a study diary to note any side effects experienced or concurrent medications taken. The NCI Common Terminology Criteria for Adverse Events version 4.0 was used to grade adverse events. For drugrelated toxicities $\geq$ grade 3 , both study drugs were withheld until toxicities recovered to $\leq$ grade 2 ; upon re-initiation, the FdCyd dose was reduced per protocol depending on the degree of toxicity. Tumor response was assessed by radiography at baseline and every 2 cycles thereafter and evaluated per RECIST version 1.1 [28].

\section{Pharmacokinetics}

See Supplementary Methods for information regarding pharmacokinetic analyses.

\section{Preclinical validation of a CellSearch ${ }^{\circledR}$ assay for CTC p16 expression following FdCyd + THU treatment}

Methodology and results concerning the development and preclinical validation of a CellSearch ${ }^{\circledR}$ assay to quantitate the proportion of p16-expressing tumor cells are described in the Supplementary Methods, with data shown in Supplementary Fig. S1.

\section{CellSearch ${ }^{\circledast}$ analysis of CTC $p 16$ expression in patient blood specimens}

\section{Sample collection and processing}

Blood specimens (7.5 mL each) were collected for CTC analysis at the following time points: prior to drug administration on cycle 1 day 1 (C1D1); on cycle 1 day 2 (C1D2; up to $24 \mathrm{~h}$ after end of infusion); on cycle 1 day 12 (C1D12); and on day 1 and day 12 of cycles 2, 4, and 6. Blood was collected into 10-mL CellSave Preservative Tubes (Menarini Silicon Biosystems). Tubes were inverted 8 times to distribute the anticoagulant and preservative and then stored at room temperature (for up to $96 \mathrm{~h}$ ) until processing. Each blood sample was mixed with dilution buffer from the CellSearch ${ }^{\circledR}$ Circulating Endothelial Cell (CEC) Kit (Menarini Silicon Biosystems) to a total volume of $14 \mathrm{~mL}$, and then centrifuged and processed using the CellSearch ${ }^{\circledR}$ platform. CTCs were assessed using an in-house-laboratory-developed test entailing dual capture of CTCs using CellSearch ${ }^{\circledR}$ anti-EpCAM - and anti-MCAM (CD146)-coated beads, anti-CD45 antibodies to exclude PBMCs from the analysis, anti-pan-cytokeratin, and custom conjugated antibodies to detect p16, the mesenchymal marker vimentin (VIM), and the tumor marker mucin 1 (MUC1): AF 488-conjugated anti-p16 (clone EP435Y-129R, Abcam, Cambridge, UK), phycoerythrin (PE)-conjugated anti-vimentin (clone V9, Santa Cruz Biotechnology, Dallas, TX), and PerCP-Cy5.5conjugated anti-MUC1 (clone number E29, Santa Cruz Biotechnology). The E29 anti-MUC1 monoclonal antibody binds to a portion of the MUC1 tandem repeat sequence in a glycosylation-independent fashion [29, 30]. This method captures circulating cells that are either EpCAM- or CD146positive, identifies captured cells that express MUC1, and can identify high numbers of PD biomarker/MUC1-doublepositive cells. Importantly, our pilot analysis of 18 healthy donor blood specimens (6 donors, three 7.5-mL specimens per donor) found no $\mathrm{CK}^{+} / \mathrm{MUC}^{+} / \mathrm{DAPI}^{+} / \mathrm{CD}^{-} 5^{-}$or $\mathrm{VIM}^{+} /$ $\mathrm{MUC}^{+} / \mathrm{DAPI}^{+} / \mathrm{CD} 45^{-}$cells in these specimens, demonstrating the specificity of this assay for circulating tumor cells.

\section{CTC classification}

Images captured by the 5-Color System in CellTracks ${ }^{\circledR}$ Analyzer II contain objects fulfilling predetermined criteria and are automatically presented in gallery format. Final classification of cells was performed independently by two operators. Cells were classified as CTCs when morphologic features and staining patterns were consistent with that of epithelial-phenotype circulating tumor cells (i.e., CK-positive, DAPI-positive, CD45-negative, and tumor marker [MUC1]-positive) or putative mixed E/M-phenotype circulating tumor cells (vimentin-positive, DAPI-positive, CD45-negative, and tumor marker-positive). CTCs were required to have a minimum size of at least $4 \mu \mathrm{m}$, though CTCs presented with substantial heterogeneity in size and morphology. 


\section{Pharmacodynamic analyses in cytokeratin- or vimentin-positive CTCs}

Serial baseline samples from individual patients (collected on C1D1 and C1D2) were used to determine variability in baseline levels of CTCs and changes in vimentin-, cytokeratin-, and/or p16-positive CTCs in response to treatment. Patients were prospectively designated as assessable for vimentin-positive $\left(\mathrm{VIM}^{+}\right)$or cytokeratin-positive $\left(\mathrm{CK}^{+}\right)$ CTC p16 response if at least one of the baseline patient blood specimens (i.e., C1D1 and/or C1D2) contained $\geq 6$ CTCs, and at least one post-treatment patient blood specimen (i.e., specimens collected C1D12 or later) contained $\geq 6$ CTCs. Six CTCs was selected as the cut-off to minimize errors in p16 expression classification due to small sample size. For examining changes in p16 prevalence, both C1D1 and C1D2 samples were prospectively considered baseline specimens to obtain more accurate measurements, given the known variability in baseline CTC count; for patients with specimens from both time points, we took a stringent approach by assigning the specimen with the highest frequency of CTC p16 expression as the baseline specimen for assessing post-treatment p16 positivity. Patients were designated as having undergone an increase in the proportion of p16-expressing CTCs according to the following prospectively defined criteria: if the percentage of p16-positive CTCs increased by at least threefold (or from 0 to $\geq 2$ p16-positive CTCs in specimens containing $\geq 6$ CTCs each) in one or more post-treatment specimens relative to baseline.

\section{Statistical analysis}

The study was designed to include co-primary endpoints of ORR and PFS, with a successful outcome in either parameter designating the regimen as worthy of further testing. The study design was intended to discriminate between response rates of $20 \%$ versus $5 \%$ or 4 -month (or, for the breast stratum, 6-month) PFS probabilities of 50\% vs. 25\% (corresponding to median PFS of 4 vs. 2 months, or, for the breast cancer stratum, 6 vs. 3 months); see Supplementary Materials for additional details. Based on survival and response metrics from prior studies (see Supplementary Materials), FdCyd combined with THU was designated as worthy of further testing in NSCLC, urothelial, or $\mathrm{H} \& \mathrm{~N}$ cancer if $\geq 6$ objective responses $(\geq 13 \%)$, or $\geq 18$ instances of 4-month PFS ( $\geq 40 \%$ ), were observed among 45 enrolled patients; for the breast stratum, the regimen was considered worthy of further testing if $\geq 5$ objective responses ( $\geq 14 \%$ ), or $\geq 15$ instances of 6-month PFS ( $\geq 43 \%$ ), were observed among 35 enrolled patients. Design of the NSCLC, urothelial, and $\mathrm{H} \& \mathrm{~N}$ strata included provisions for the early termination due to insufficient antitumor activity: if no more than one objective response $(\leq 5 \%)$, and no more than six instances of 4-month PFS $(\leq 30 \%)$, were observed among the initial 20 patients.

ORR was calculated by dividing the number of responses by the number of eligible patients, per RECIST version 1.1 [28]. PFS was calculated from the start of therapy until date of progression or death without progression, using the Kaplan-Meier method. Patients who were taken off study for refusal of further treatment, intercurrent illness, PI discretion, or other were censored at the date therapy ended.

A log-rank test was used to assess associations between baseline $\mathrm{CK}^{+} \mathrm{CTC}$ count and PFS. A Fisher's exact test was used to compare the clinical response rate ( $\mathrm{PR}+$ stable disease [SD], vs. progressive disease [PD]) between patients with versus those without an increase in the proportion of p16-expressing $\mathrm{CK}^{+} \mathrm{CTCs}$; patients with high frequencies of CTCs positive for $\mathrm{p} 16(\geq 15 \%)$ at baseline were omitted from the analysis. All $p$ values are two-tailed.

\section{Results}

\section{Patient demographics}

From September 2009 through December 2017, 95 patients were enrolled on this study; 93 were eligible, including 29 breast, 25 NSCLC, $21 \mathrm{H} \& \mathrm{~N}$, and 18 urothelial cancer patients (Table 1 and Supplementary Fig. S2). The median patient age was 60 years (range $30-84$ years). The patient population was heavily pre-treated, with a median of 6 prior

Table 1 Patient characteristics

\begin{tabular}{ll}
\hline Characteristics & Number of patients \\
\hline $\begin{array}{l}\text { Number of patients enrolled/eligible/evaluable } \\
\text { for response }\end{array}$ & $95 / 93 / 83$ \\
Median age, years (range) & $60(30-84)$ \\
Karnofsky performance status (\%) & \\
100 & 12 \\
90 & 28 \\
80 & 35 \\
70 & 16 \\
60 & 3 \\
Diagnosis (eligible/evaluable for response) & \\
Breast & $29 / 28$ \\
NSCLC & $25 / 24$ \\
Head and neck & $21 / 16$ \\
Urothelial & $18 / 15$ \\
Median number of prior therapies (range) & $6(1-25)$ \\
\hline
\end{tabular}


therapies (median by stratum: breast, 10; NSCLC, 5; H\&N, 4; urothelial, 3.5).

\section{Toxicity}

Intravenous FdCyd combined with THU was well tolerated. As observed in the phase 1 study of this combination [15], the most commonly occurring drug-related grade $3 / 4$ adverse events were hematologic toxicities, with gastrointestinal toxicities also prevalent (Supplementary Table S1).

\section{Efficacy}

Of the 93 patients, 83 were evaluable for objective response. Of the 10 patients who went off study prior to response assessment, 5 refused further treatment, 3 experienced toxicity, 1 experienced intercurrent illness, and 1 died of cardiac arrest possibly due to FdCyd (Supplementary Fig. S2). Best response and number of treatment cycles completed for each patient evaluable for objective response are shown in Fig. 1, along with Kaplan-Meier curves denoting PFS for all 93 patients across the 4 strata. Objective response rates were calculated based on the number of eligible patients, per current RECIST guidelines [28]. Three patients (1 urothelial, 2 breast) experienced a PR, for an overall objective response rate of $3.2 \%$; ORRs for individual strata were $5.6 \%, 6.9 \%, 0 \%$, and $0 \%$ for urothelial, breast, H\&N, and NSCLC, respectively (Table 2 and Fig. 1). The median PFS for all strata combined was 3.1 months (95\% confidence interval [CI] 1.8-3.7 months); median PFS values (and 95\% CI) for individual strata were 3.6 (1.7-8.0), 3.7 (1.8-5.3), 1.7 (1.7-4.5), and 2.3 (1.6-3.9) months for urothelial, breast, H\&N, and NSCLC, respectively. Four-month PFS probabilities (and 95\% CI) for the urothelial, H\&N, and NSCLC strata were 42.0 (16.2-66.1), 29.0 (10.0-51.5), and 27.5 (11.2-46.6), respectively, while the 6-month PFS probability for the breast stratum was 26.2 (95\% CI 10.9-44.4) (Table 2). Based on response rate and PFS data, and per predefined early termination rules, the NSCLC and H\&N strata were closed early due to insufficient antitumor activity.

The breast and urothelial strata were ultimately closed due to insufficient accrual (Table 1); this precluded comprehensive statistical comparisons of response and PFS probabilities relative to predefined thresholds specified in the protocol, which were based on enrollment of 35 and 45 evaluable patients for the breast and urothelial strata, respectively. Though accrual goals were not met for these strata, preliminary results suggest that further testing of FdCyd + THU in urothelial transitional cell carcinoma may be warranted, given the 4-month PFS probability of $42 \%$ (versus the predefined target probability of $\geq 40 \%$ ) in the first 18 urothelial patients; however, the ORR of $5.6 \%$ did not meet the predefined target rate of $\geq 13 \%$ (Tables 1 and 2 ). Preliminary results for the breast stratum do not support further testing of FdCyd + THU in this disease $(6.9 \%$ ORR and 26.2\% 6-month PFS probability in the first 29 patients, versus predefined target values of $\geq 14 \%$ and $\geq 43 \%$, respectively).

\section{Pharmacokinetic analysis}

Plasma pharmacokinetic parameters were assessed for a subset of patients as described in the Supplementary Materials, and the resulting values (Supplementary Table S2 and Supplementary Fig. 3) were similar to those previously reported for IV administration of the same doses in the prior phase 1 study [15].

\section{Pharmacodynamic analysis}

\section{Cytokeratin-positive CTC enumeration}

Though the presence of CTCs in baseline blood specimens is known to be of prognostic value in various indications [31-37], we found no significant association between pretreatment (C1D1) cytokeratin-positive $\left(\mathrm{CK}^{+}\right) \mathrm{CTC}$ count and PFS amongst patients with pre-treatment CTC specimens (Supplementary Fig. S4a, b). Furthermore, median post-treatment changes in $\mathrm{CK}^{+} \mathrm{CTC}$ counts did not appear to be appreciably different across categories of best response to therapy (PR, SD, or PD), though interpatient heterogeneity in CTC number was high (Supplementary Fig. S4c), as has been observed previously $[31,34,38]$.

\section{Cytokeratin-positive CTC $p 16$ expression}

Of the 83 patients evaluable for clinical response, 29 $(35 \%)$ were also evaluable for changes in the proportion of p16-expressing $\mathrm{CK}^{+}$CTCs according to our prospectively defined criteria (see Materials and Methods). The majority of patients who were not evaluable for p16 CTC response $(87 \%$; 47/54) did not have sufficient numbers of CTCs present at baseline and/or any post-treatment time point, while the remaining $13 \%$ (7/54) were lacking baseline and/or posttreatment blood specimens for CTC analysis.

Blood specimens for baseline p16 CTC analysis were collected on both C1D1 and C1D2 to address the known intra-patient variability in baseline CTC count and to account for drug-induced CTC showering that can occur in some patients [23, 38]. DNMT inhibitors such as FdCyd require an extended timeframe for activity, given that transition through $\mathrm{S}$ phase of the cell cycle is needed to enable 

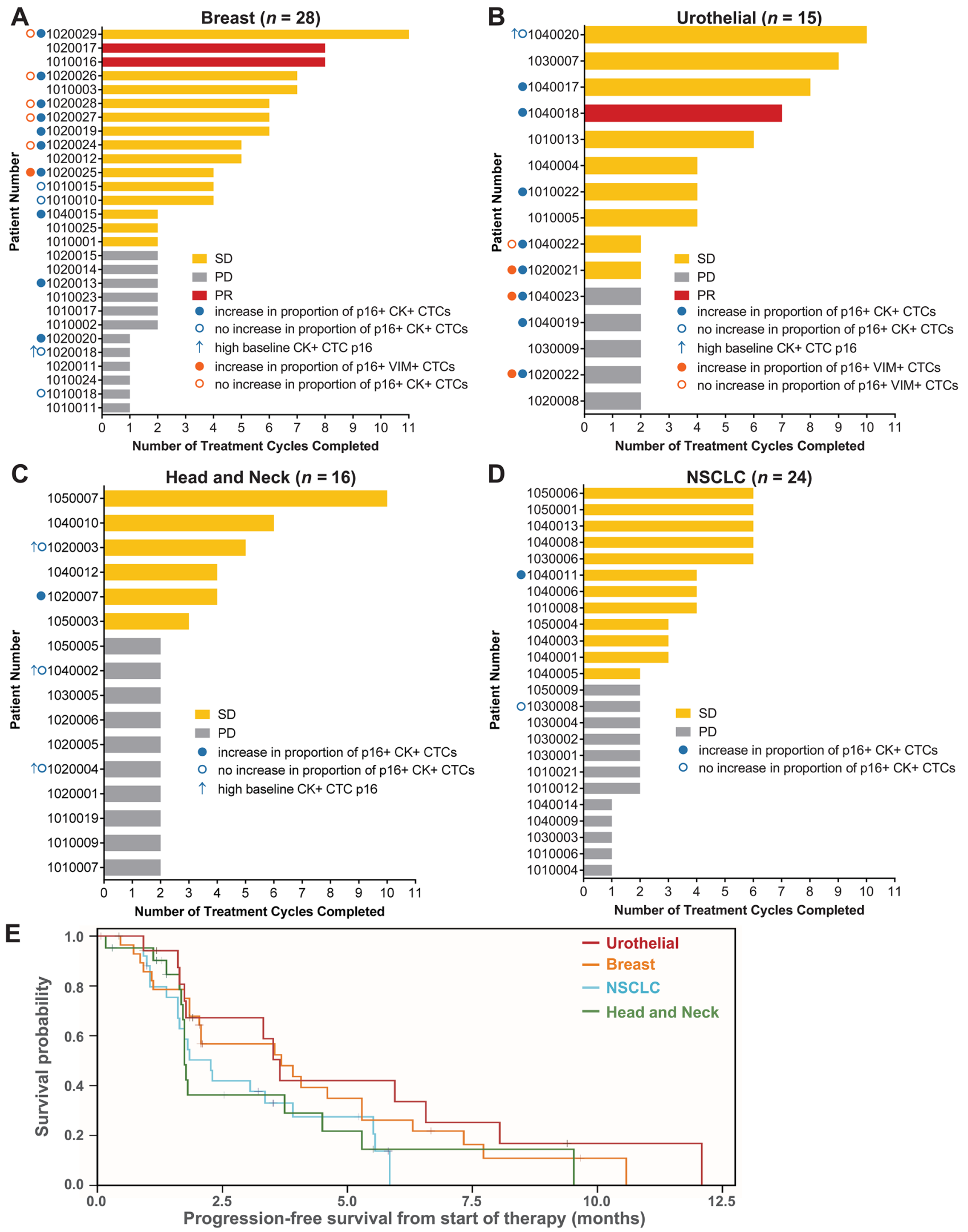
4Fig. 1 Clinical response and progression-free survival following FdCyd + THU therapy, by tumor type. a-d The number of cycles of treatment completed is shown for each patient evaluable for objective response, and patients for each tumor type stratum are shown (a breast; b urothelial; $\mathbf{c}$ head and neck; d NSCLC) along with the best response to therapy (partial response, red; stable disease, yellow; progressive disease, gray). Patients who did or did not exhibit an increase in the proportion of p16-expressing CTCs are indicated by filled or open circles, respectively, with orange circles indicating $\mathrm{VIM}^{+} \mathrm{CTCs}$ and blue indicating $\mathrm{CK}^{+}$CTCs; patients with high baseline p16 expression in $\mathrm{CK}^{+} \mathrm{CTCs}$ are indicated by blue arrows. Patients with no circle shown were not evaluable for CTC p16 response. e KaplanMeier progression-free survival curves are shown for each stratum and include data for all 93 enrolled patients

inhibitor incorporation into DNA, and human tumors exhibit relatively slow progression through the cell cycle-resulting in tumor volume doubling times in the range of weeks to months [39]. In addition, prior experiments have shown that even in vitro, DNMT inhibitor-induced p16 protein expression in tumor cells occurs only after a $24-48$-h lag period following treatment [40], and our EJ6 cell culture data show that appreciable upregulation of $\mathrm{p} 16$ protein expression (detected by Western blot) occurs beginning at 2 weeks after a single application of FdCyd + THU (Supplementary Figure S1a). Because of this extended timeframe for FdCyd-induced epigenetic effects, differences in CTC p16 expression on C1D1 vs. C1D2 are assumed to reflect baseline heterogeneity in p16 expression rather than pharmacodynamic effects. We took a conservative approach in defining treatment-induced increases in the proportion of p16-expressing CTCs, using the higher of the 2 C1D1 and C1D2 values as the baseline value. For the majority of patients evaluable for p16 response (51.7\%; 15 of 29), the percent of $\mathrm{CK}^{+} \mathrm{CTC}$ expressing p16 was identical for the C1D1 and C1D2 specimens; 6 patients (20.7\%) did not have an evaluable CTC blood specimen for 1 of the 2 baseline time points, and of the remaining 8 patients (27.6\%), the median difference in \% CTCs expressing p16 between the 2 time points was $1 \%$ (range -1 to $33 \%$ ).

In selecting a prospective cut-off to define an increase in the proportion of p16-expressing CTCs, we used a $\geq$ threefold increase in the percentage of p16-expressing CTCs at any post-treatment time point, compared to baseline specimens (C1D1 or C1D2, as described above). For patients with no p16-expressing CTCs at baseline, an increase to $\geq 2$ CTCs (in a specimen containing $\geq 6$ CTCs) was used to define an increase in the proportion of p16-expressing CTCs. A treatment-induced increase in the proportion of p16-expressing $\mathrm{CK}^{+}$CTCs was observed in 20 of 29 patients (69\%) evaluable for both clinical response and changes in p16 expression (Table 3, Figs. 1 and 2). An increase in the proportion
Table 2 Objective response rates and progression-free survival by stratum

Table 3 Patient response and therapy-associated increases in $\mathrm{CK}^{+}$CTC 16 positivity

\begin{tabular}{llll}
\hline Stratum & ORR, \% (95\% CI) & $\begin{array}{l}\text { Median PFS, months } \\
(95 \% \mathrm{CI})\end{array}$ & $\begin{array}{l}\text { 4- or 6-month }{ }^{\mathrm{a}} \text { PFS } \\
\text { probability, \% (95\% } \\
\text { CI) }\end{array}$ \\
\hline Overall (all 4 strata) & $3.2(0.7-9.1)$ & $3.1(1.8-3.7)$ & \\
Breast & $6.9(0.8-22.8)$ & $3.7(1.8-5.3)$ & $26.2(10.9-44.4)$ \\
Urothelial & $5.6(0.1-27.3)$ & $3.6(1.7-8.0)$ & $42.0(16.2-66.1)$ \\
Head and neck & $0.0(0-16.1)$ & $1.7(1.7-4.5)$ & $29.0(10.0-51.5)$ \\
NSCLC & $0.0(0.0-13.7)$ & $2.3(1.6-3.9)$ & $27.5(11.2-46.6)$ \\
\hline
\end{tabular}

ORR was calculated by dividing the number of responses by the total number of eligible patients

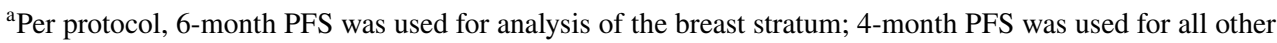
strata

\begin{tabular}{|c|c|c|c|}
\hline & PD & SD & PR \\
\hline \multicolumn{4}{|l|}{$\begin{array}{l}\text { All patients evaluable for clinical response and CTC p16 expression } \\
\text { changes }(n=29)\end{array}$} \\
\hline No. pts with increase in proportion of p16-expressing CTCs & 5 & 14 & 1 \\
\hline No. pts with no increase in proportion of p16-expressing CTCs & 5 & 4 & 0 \\
\hline \multicolumn{4}{|l|}{ Patients with high baseline p16 removed $(n=24)$} \\
\hline No. pts with increase in proportion of p16-expressing CTCs & 5 & 14 & 1 \\
\hline No. pts with no increase in proportion of p16-expressing CTCs & 2 & 2 & 0 \\
\hline
\end{tabular}

Among the 24 patients with low baseline p16 expression, no significant difference in the rate of PR $+\mathrm{SD}$ was observed for patients with an increase in the proportion of p16-expressing $\mathrm{CK}^{+} \mathrm{CTCs}$ vs. those without $(p=0.55)$ 
A

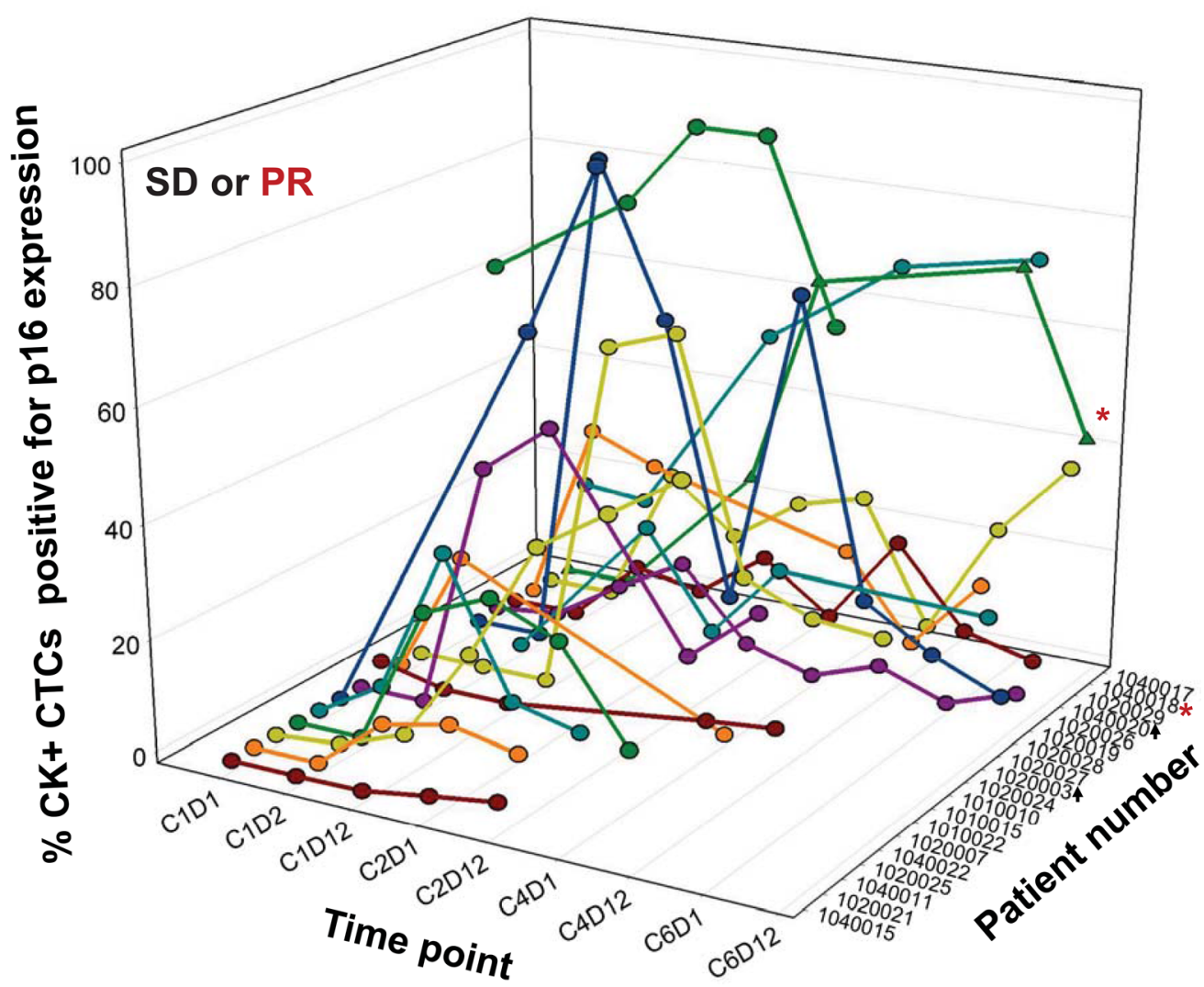

B

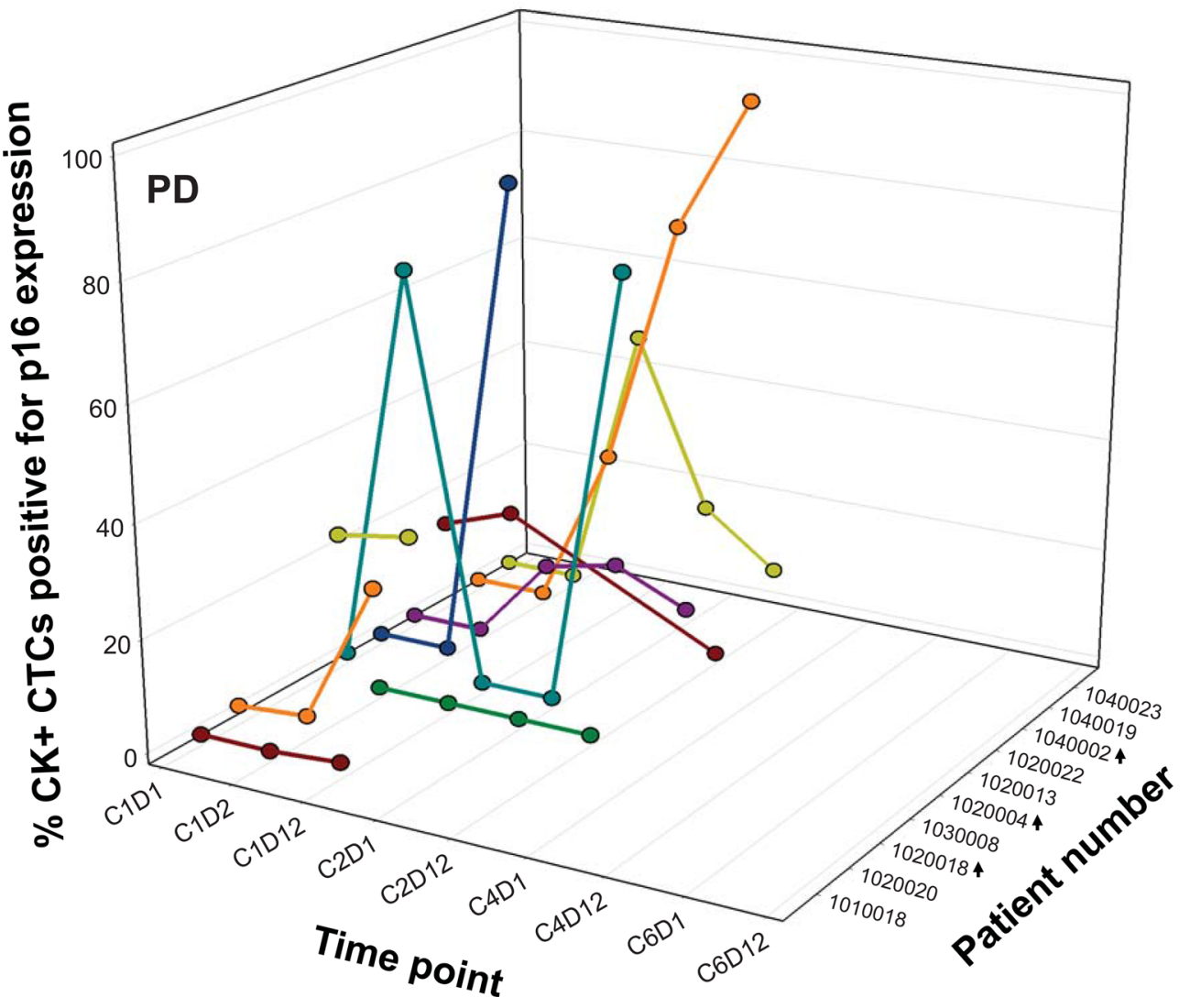


4Fig. $2 \mathrm{FdCyd}+\mathrm{THU}$ treatment increases the proportion of p16-expressing cytokeratin-positive circulating tumor cells. The percentages of $\mathrm{CK}^{+}$CTCs also positive for p16 expression are shown at each time point (cycle, day) for all patients evaluable for both clinical response and CTC p16 expression, including patients with a best response of a stable disease (SD) or partial response (PR) or b progressive disease (PD). Each set of identically colored symbols and connecting lines represents data from a single patient. The patient who experienced a PR is indicated by a red asterisk (with data points shown as triangles), while patients with high baseline (C1D1 and/ or C1D2 values $\geq 15 \%$ ) p16 expression are denoted by black arrows. Within each graph, patients are ordered by increasing number of treatment cycles completed, from front to back

of p16-expressing $\mathrm{CK}^{+}$CTCs was observed at the earliest non-baseline time point (C1D12) for most patients (Fig. 2).

Of the 9 patients for whom no increase in the proportion of p16-expressing $\mathrm{CK}^{+}$CTCs was observed at any time point, 5 had a high proportion $(\geq 15 \%)$ of $\mathrm{p} 16$-positive $\mathrm{CK}^{+}$cells at baseline (Table 3, Figs. 1 and 2), and these patients were omitted in the statistical analysis of associations between clinical response and treatment-induced increases in the proportion of p16-expressing $\mathrm{CK}^{+} \mathrm{CTCs}$; the other 4 patients with no increase in the proportion of p16-expressing $\mathrm{CK}^{+}$CTCs had low baseline p16 expression $(<15 \%)$ and were included in the analysis of p16 expression changes and clinical response. In addition, one patient with a PR in the breast stratum (patient 1,020,017) and one patient with extended stable disease in the $H \& N$ stratum (patient 1,050,007) were classified as not evaluable for $\mathrm{p} 16$ CTC response, because they did not have a sufficient number of CTCs at baseline; however, these patients had evaluable numbers of CTCs at multiple later time points, and an increase in the proportion of p16-expressing $\mathrm{CK}^{+} \mathrm{CTCs}$ was observed at these later time points (Figs. 1 and 2).

Of the 24 patients with low baseline p16 expression in $\mathrm{CK}^{+} \mathrm{CTCs}$, an increase in the proportion of p16-expressing $\mathrm{CK}^{+}$CTCs was observed in 2 of $2(100 \%)$ patients with a best response of PR, 13 of $15(87 \%)$ patients with SD, and 5 of $7(71 \%)$ of patients with PD (Table 3); however, the presence of just 4 patients with no increase in the proportion of p16-expressing $\mathrm{CK}^{+}$CTCs limits the statistical power for examining associations between response and p16 expression. When comparing patients with a treatment-induced increase in the proportion of p16-expressing $\mathrm{CK}^{+} \mathrm{CTCs}$ vs. those without, the resulting differences in $\mathrm{PR}+\mathrm{SD}$ rates (75\% vs. 50\%) were not significant $(p=0.55)$. Therefore, although the clinical response rates for the two groups suggest that there may be modest prognostic value to an increased proportion of p16-expressing $\mathrm{CK}^{+} \mathrm{CTCs}$, the sample size is too small to achieve statistical significance. Likewise, sample sizes were too small to adequately evaluate histologic stratum-specific differences in $\mathrm{CK}^{+}$CTC p16 response; however, 3 of 5 patients with high baseline p16 expression were from the H\&N stratum (Fig. 1c), consistent with the high prevalence of p16 expression in tumors from H\&N patients infected with human papilloma virus (HPV) [41].

\section{Characterization of vimentin-positive CTCs}

While CTC analyses have typically relied upon selection of epithelial-phenotype CTCs via EpCAM, CK, or other epithelial markers, mesenchymal- and mixed epithelial/ mesenchymal-phenotype CTCs are, a priori, more consistent with the characteristics of metastatic tumor cells, including enhanced motility, invasiveness, and self-renewal [42]; indeed, data from several recent studies across multiple tumor types have suggested that mesenchymal- or mixed E/M-phenotype CTCs may be of greater prognostic and/or predictive value than their epithelial-phenotype counterparts [24-27]. Following the emergence of this information regarding the potential predictive value of mesenchymal- or mixed E/M-phenotype CTCs, we developed and validated a novel custom CellSearch ${ }^{\circledR}$ assay to assess p16 expression in the putative mixed E/M-phenotype subpopulation. Because assay validation was completed during the late stages of this trial, we performed a pilot analysis of putative mixed E/Mphenotype CTCs in 13 of the final patients enrolled, employing MUC1 as a tumor marker as has been done in several prior CTC studies [43-45], and enumerating and measuring p16 expression in $\mathrm{VIM}^{+}, \mathrm{MUC1}^{+}, \mathrm{DAPI}^{+}$, and $\mathrm{CD}^{4} 5^{-}$cells from peripheral blood specimens. To assess all 5 markers, we implemented and validated a novel 5-color CellSearch ${ }^{\circledR}$ assay (Supplementary Fig. S5a), which was made possible by a technological upgrade of the CellSearch ${ }^{\circledR}$ system to add a fifth fluorescence channel. We established concordance between the 4- and 5-channel CellSearch ${ }^{\circledR}$ systems for CTC enumeration and PD response evaluation (Supplementary Fig. S5b-e).

In general, there were substantially more $\mathrm{VIM}^{+} / \mathrm{MUC1}^{+} /$ $\mathrm{DAPI}^{+} / \mathrm{CD}^{2} 5^{-}$cells (hereafter referred to as "VIM ${ }^{+} \mathrm{CTCs}$ ") compared to $\mathrm{CK}^{+} / \mathrm{MUC}^{+} / \mathrm{DAPI}^{+} / \mathrm{CD} 45^{-}$cells (" $\mathrm{CK}{ }^{+}$ CTCs") across all patients and time points (Supplementary Fig. S6a); the average ratio of $\mathrm{VIM}^{+}: \mathrm{CK}^{+} \mathrm{CTC}$ was 13.8 (median: 4.7; minimum: 0; maximum: 200.2). For several patients, the number of $\mathrm{VIM}^{+}$CTCs appeared to increase in the cycle prior to their progression on FdCyd + THU, though the small sample size precludes adequately powered statistical analyses (Supplementary Fig. S6a).

We also examined p16 expression in $\mathrm{VIM}^{+}$CTCs, using the criteria described for $\mathrm{CK}^{+} \mathrm{CTCs}$, and compared $\mathrm{p} 16$ expression patterns in $\mathrm{VIM}^{+}$vs. $\mathrm{CK}^{+}$CTCs. Twelve of thirteen patients were assessable for both $\mathrm{CK}^{+}$and $\mathrm{VIM}^{+}$ CTC p16 expression changes, indicating that our laboratory-developed test-even with its requirement for tumor marker positivity - detected adequate $\mathrm{CK}^{+} \mathrm{CTC}$ numbers $(\geq 6)$ in a higher proportion of patients compared to the 

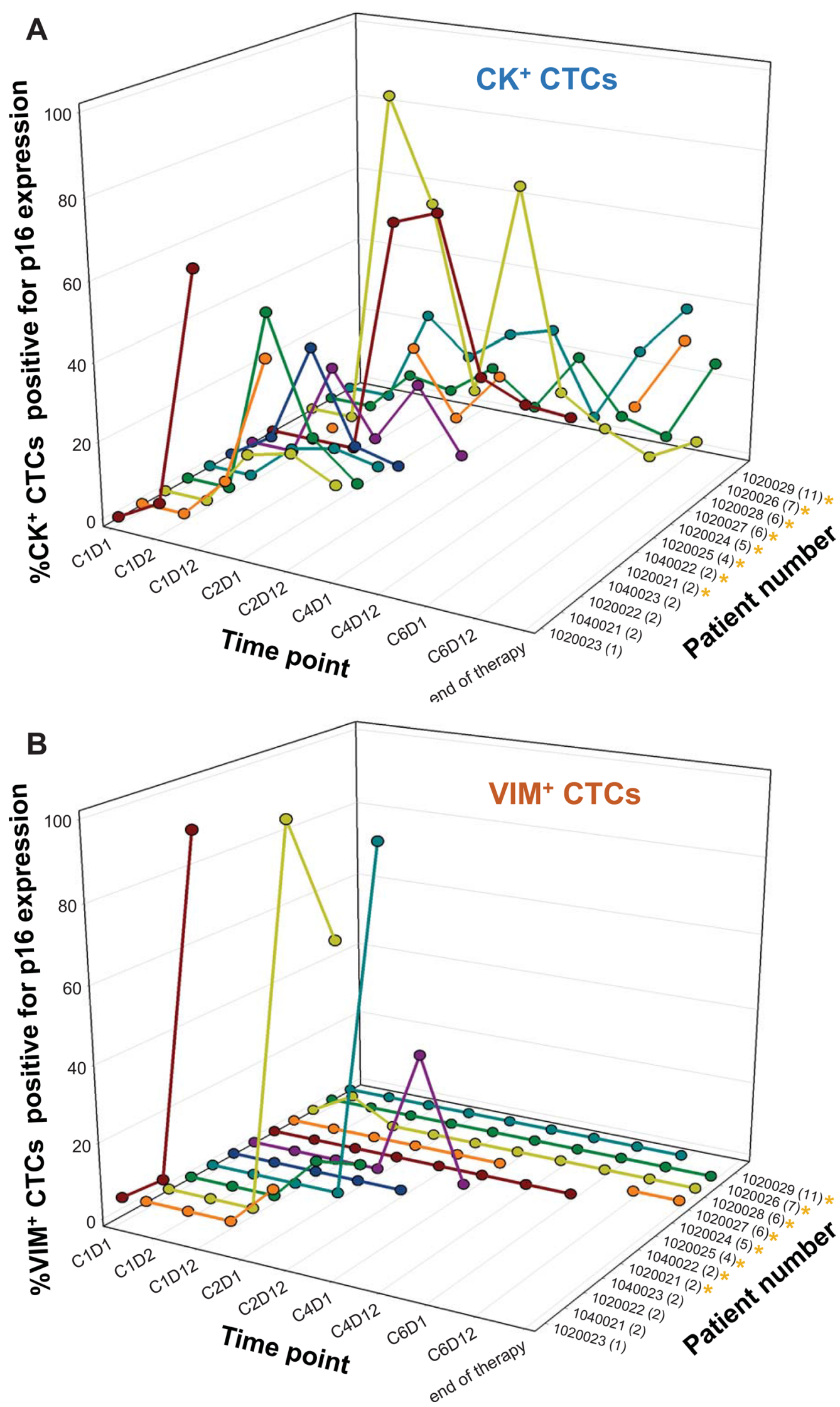
4Fig. 3 P16 expression in cytokeratin-positive versus vimentinpositive CTCs. Percentages of p16-positive CTCs of a epithelial phenotype $\left(\mathrm{CK}^{+}\right)$or putative epithelial/mesenchymal mixed phenotype $\left(\mathrm{VIM}^{+}\right)$are shown at each time point for each of 12 patients with CTC specimens evaluable for both $\mathrm{CK}^{+}$and $\mathrm{VIM}^{+}$CTC p16 response. Each set of colored symbols and connecting lines represents data from a single patient; order/coloring of patients is the same in $(\mathbf{a}, \mathbf{b})$. The number of cycles of therapy completed is noted in parentheses next to each patient number along the $x$ axis. Gold asterisks denote patients with a best response of stable disease

4-channel CellSearch ${ }^{\circledR}$ assay. Of these 12 patients, 6 (50\%) did not show an increase in the proportion of p16-expressing $\mathrm{VIM}^{+}$CTCs at any post-treatment time point; in contrast, an increase in the proportion of p16-expressing $\mathrm{CK}^{+} \mathrm{CTCs}$ was observed for all 12 patients (Supplementary Fig. S6b). In addition, increases in the proportion of p16-expressing $\mathrm{VIM}^{+}$CTCs, when they did occur, were slightly delayed relative to such changes in $\mathrm{CK}^{+}$CTCs (Supplementary Fig. $\mathrm{S} 6 \mathrm{~b})$. Increases in the proportion of p16-expressing $\mathrm{VIM}^{+}$ CTCs did not seem to be indicative of response to therapy, as some of the longest durations of stable disease in breast cancer patients occurred in patients for which no increase in the proportion of p16-expressing $\mathrm{VIM}^{+}$CTCs was observed, and all 4 response-assessable urothelial patients with $\mathrm{VIM}^{+}$ CTC data were on study for just 2 cycles of treatment, regardless of $\mathrm{VIM}^{+} \mathrm{CTC}$ p16 expression status (Figs. 1 and $3)$.

\section{Discussion}

Our efficacy results suggest that further testing of the FdCyd + THU combination is potentially warranted only in patients with urothelial transitional cell carcinoma, but not in NSCLC, H\&N cancer, or breast cancer. Lack of sufficient antitumor activity in the NSCLC and H\&N strata warranted early termination of both, while preliminary results for the 29 patients in the breast stratum also indicated insufficient activity for further analysis. For the 18-patient urothelial stratum, the low ORR indicated insufficient activity, but the 4-month PFS probability essentially met the predefined cutoff selected to designate promising activity (though the cutoff was designed assuming accrual of 45 evaluable patients). Future studies of FdCyd + THU in a sufficient number of urothelial transitional cell carcinoma patients could enable more precise determination of the response rate and PFS; however, given the recent success of immune checkpoint inhibitors in this disease, further testing of FdCyd + THU should focus on a checkpoint blockade-refractory or -ineligible patient population. One limitation of the current study that may have impacted patient accrual and retention was the intravenous administration schedule, which required a total of ten 3-h infusions per month; this issue has been addressed by the development of an oral FdCyd formulation [13], and a phase 1 multicenter study of oral FdCyd + oral THU (NCT01534598) is ongoing [46].

While the multifaceted biological effects of DNMT inhibition complicate determination of the precise molecular basis for differences in FdCyd activity across strata, data from prior mechanistic studies may help to explain our results. Modest antitumor activity in our breast cancer patients may have been due to the varying relationship between DNA methylation and prognosis that has been observed across breast cancer subtypes [47, 48]; for example, DNA hypomethylation, rather than hypermethylation, is associated with poor survival in triple-negative breast cancer [47]. In addition, p16 overexpression, rather than loss, has been shown to correlate with hormone receptor negativity and poor outcome in some breast cancer patients $[49,50]$. For NSCLC and H\&N cancer, heterogeneity in the gene expression patterns driving malignancy may account for the lack of FdCyd + THU activity. For example, the prevalence of tumor p16 expression in HPV-positive H\&N patients suggests that $\mathrm{p} 16$ silencing is not a driver of disease in these patients; in addition, a genome-wide DNA methylation analysis of H\&N squamous cell carcinomas found substantial tumor DNA hypomethylation associated with HPV positivity, including hypomethylation of binding sites for the oncogenic transcription factor c-MYC [51]. Therefore, DNMT inhibitor-induced hypomethylation may not be a viable mechanism to control tumor growth in HPV-positive $\mathrm{H} \& \mathrm{~N}$ cancers. In NSCLC, histologic subtype variations in the hypermethylation of p16 and other tumor suppressor genes [52] may account for lack of FdCyd clinical activity. We employed the CellSearch ${ }^{\circledR}$ system for our primary correlative objective of monitoring pharmacodynamic responses to FdCyd + THU, though we also used this platform to assess the prognostic value of baseline CTC number based on results from the previous studies, showing that high baseline CTC counts are associated with poor survival [31-37] and, in some cases, with high tumor burden specifically [37, 53, 54]. Unlike these prior studies demonstrating the prognostic value of baseline CTC count, we found no association between pre-treatment $\mathrm{CK}^{+} \mathrm{CTC}$ number and PFS, which may be due in part to the smaller sample size and more advanced disease status of patients in this study, particularly given the distribution of these patients across 4 different tumor types; prior studies demonstrating a prognostic value for baseline CTC count have largely focused on a single indication and various disease stages therein.

For pharmacodynamic analyses of CTCs, p16 was selected as a PD biomarker based on extensive prior literature, as well as our preclinical validation of antibody specificity and FdCyd-induced p16 expression changes. Use of the CellSearch ${ }^{\circledR}$ platform for CTC pharmacodynamic analyses has several caveats, including the relatively low numbers 
of isolated EpCAM- or CK-expressing cells [23]. Indeed, we were able to identify many more $\mathrm{VIM}^{+}$CTCs relative to $\mathrm{CK}^{+} \mathrm{CTCs}$, and this technological feasibility, combined with the greater potential biological relevance of mesenchymal or mixed E/M-phenotype CTCs in patients with metastatic disease, suggests that analysis of this CTC population may enable generation of more statistically robust and informative data in future studies. The CellSearch ${ }^{\circledR}$ platform is also limited by the availability of just 5 channels for analysis (and only 4 channels at the time of study initiation), rendering full exploration of biological processes difficult; for example, the limited number of channels precluded measuring vimentin and $\mathrm{CK}$ simultaneously, preventing thorough analysis of mixed epithelial/mesenchymal phenotypes, as has been performed in the other studies [24-27].

We detected treatment-induced increases in the proportion of p16-expressing cytokeratin-positive CTCs for the majority (69\%) of patients evaluable for both clinical response and CTC $\mathrm{p} 16$ expression changes, including in all such patients with low baseline p16 expression and a best response of $\mathrm{PR}$ or prolonged $\mathrm{SD}$; however, an increase in the proportion of p16-expressing $\mathrm{CK}^{+} \mathrm{CTC}$ s was not significantly associated with clinical response. Considering the relatively small sample size and limited number of responses, as well as the complexity of proposed mechanisms of action for cytidine analogs via general $\mathrm{CpG}$ island demethylation, this was not a surprising finding. One potential factor contributing to the small number of patients evaluable for p16 CTC response may have been specimen integrity; our recent analyses have demonstrated that CTC specimens must be processed within $72 \mathrm{~h}$ of collection to yield a sufficient number of assessable CTCs, and several early specimens (31 out of the 496 collected) were not processed within this $72-\mathrm{h}$ time frame.

These CTC results provide the evidence of the expected pharmacodynamic effects for this regimen in restoring tumor suppressor gene expression, and are consistent with the demonstrated increases in p16 expression and/ or demethylation detected in clinical studies of decitabine in patients with solid tumor malignancies $[7,55,56]$. Of note, a similar lack of association between drug-induced increases in demethylation/expression of tumor-associated genes and clinical response was observed in a meta-analysis of 9 clinical studies of demethylating agents in solid tumor malignancies [56]. However, it is possible that an association between CTC 16 expression and response to FdCyd + THU might be observed with a larger number of patients-particularly, urothelial patients-for whom this regimen had the greatest activity in this study and for which reduced p16 expression was shown to be associated with poor prognosis in a meta-analysis of 37 studies [6].

Our pilot analysis of p16 expression in vimentin-positive CTCs revealed that increases in the proportion of p16-expressing $\mathrm{VIM}^{+}$CTCs occurred in just 6 of the 12 patients evaluable for $\mathrm{VIM}^{+} \mathrm{CTC}$ p16 expression changes, while all 12 patients exhibited increases in the proportion of p16-expressing $\mathrm{CK}^{+}$CTCs. Though small sample size is again a caveat, it appears that increases in the proportion of p16-expressing CTCs occurred slightly later (if at all) in $\mathrm{VIM}^{+} \mathrm{CTC}$ relative to their $\mathrm{CK}^{+}$counterparts. This limited or latent $\mathrm{FdCyd}$-induced increase in the proportion of p16-expressing VIM $^{+}$CTCs, if verified by larger studies, may have biological and clinical implications given the importance of mesenchymal-associated characteristics such as enhanced motility and invasion in metastatic disease, as well as the apparent prognostic value of mesenchymal CTCs suggested by the recent studies [24-27]. Future preclinical studies exploring the molecular basis for this potential resistance to FdCyd-induced p16 expression in mesenchymal- and mixed E/M-phenotype tumor cells will be valuable in determining potential combination regimens, as well as highlighting specific patient populations that may benefit from FdCyd-based therapies. Finally, assessment of FdCydinduced p16 expression changes in both CTCs and tumor biopsy specimens will be of great value in determining the adequacy of CTCs as a surrogate for tumor p16 expression, and this analysis is being performed in our ongoing phase 1 study of oral FdCyd + THU.

Acknowledgements The authors wish to thank all patients and their families for participating in this study, as well as Gurleen Kaur for excellent data management assistance and Julianne Holleran for PK sample analysis.

Funding This project has been funded in whole or in part with federal funds from the National Cancer Institute, National Institutes of Health, under Contract No. HHSN261200800001E. The content of this publication does not necessarily reflect the views or policies of the Department of Health and Human Services, nor does mention of trade names, commercial products, or organizations imply endorsement by the U.S. Government. This project was also funded in part by awards UM1CA186690, UM1-CA186717, and NO1-CM-2011-00038. This study utilized the UPMC Hillman Cancer Center, Cancer Pharmacokinetics and Pharmacodynamics Facility (CPPF), and was supported in part by awards HHSN261201100015C and P30CA047904.

\section{Compliance with ethical standards}

Conflict of interest The authors declare that they have no conflicts of interest.

Ethical approval All procedures performed in studies involving human participants were in accordance with the ethical standards of the National Institutes of Health and with the 1964 Helsinki declaration and its later amendments or comparable ethical standards.

Informed consent Informed consent was obtained from all individual participants included in the study.

Open Access This article is licensed under a Creative Commons Attribution 4.0 International License, which permits use, sharing, 
adaptation, distribution and reproduction in any medium or format, as long as you give appropriate credit to the original author(s) and the source, provide a link to the Creative Commons licence, and indicate if changes were made. The images or other third party material in this article are included in the article's Creative Commons licence, unless indicated otherwise in a credit line to the material. If material is not included in the article's Creative Commons licence and your intended use is not permitted by statutory regulation or exceeds the permitted use, you will need to obtain permission directly from the copyright holder. To view a copy of this licence, visit http://creativecommons .org/licenses/by/4.0/.

\section{References}

1. Herman JG, Baylin SB (2003) Gene silencing in cancer in association with promoter hypermethylation. N Engl J Med 349(21):2042-2054. https://doi.org/10.1056/NEJMra023075

2. Merlo A, Herman JG, Mao L, Lee DJ, Gabrielson E et al (1995) 5' $\mathrm{CpG}$ island methylation is associated with transcriptional silencing of the tumour suppressor p16/CDKN2/MTS1 in human cancers. Nat Med 1(7):686-692. https://doi.org/10.1038/nm0795-686

3. Gu J, Berman D, Lu C, Wistuba II, Roth JA et al (2006) Aberrant promoter methylation profile and association with survival in patients with non-small cell lung cancer. Clin Cancer Res 12(24):7329-7338. https://doi.org/10.1158/1078-0432. Ccr-06-0894

4. Stephen JK, Divine G, Chen KM, Chitale D, Havard S et al (2013) Significance of p16 in site-specific HPV positive and HPV negative head and neck squamous cell carcinoma. Cancer Clin Oncol 2(1):51-61. https://doi.org/10.5539/cco.v2n1p51

5. Sterlacci W, Tzankov A, Veits L, Zelger B, Bihl MP et al (2011) A comprehensive analysis of p16 expression, gene status, and promoter hypermethylation in surgically resected non-small cell lung carcinomas. J Thorac Oncol 6(10):1649-1657. https://doi. org/10.1097/JTO.0b013e3182295745

6. Gan X, Lin X, He R, Lin X, Wang H et al (2016) Prognostic and clinicopathological significance of downregulated p16 expression in patients with bladder cancer: a systematic review and meta-analysis. Dis Mark 2016:5259602. https://doi. org/10.1155/2016/5259602

7. Schrump DS, Fischette MR, Nguyen DM, Zhao M, Li X et al (2006) Phase I study of decitabine-mediated gene expression in patients with cancers involving the lungs, esophagus, or pleura. Clin Cancer Res 12(19):5777-5785. https://doi.org/10.1158/10780432.Ccr-06-0669

8. Derissen EJB, Beijnen JH, Schellens JHM (2013) Concise drug review: azacitidine and decitabine. Oncologist 18(5):619-624. https://doi.org/10.1634/theoncologist.2012-0465

9. Da Costa EM, McInnes G, Beaudry A, Raynal NJ (2017) DNA methylation-targeted drugs. Cancer J 23(5):270-276. https://doi. org/10.1097/ppo.0000000000000278

10. Smith SS, Kaplan BE, Sowers LC, Newman EM (1992) Mechanism of human methyl-directed DNA methyltransferase and the fidelity of cytosine methylation. Proc Natl Acad Sci USA 89(10):4744-4748. https://doi.org/10.1073/pnas.89.10.4744

11. Jones PA, Taylor SM (1980) Cellular differentiation, cytidine analogs and DNA methylation. Cell 20(1):85-93. https://doi. org/10.1016/0092-8674(80)90237-8

12. Beumer JH, Eiseman JL, Parise RA, Joseph E, Holleran JL et al (2006) Pharmacokinetics, metabolism, and oral bioavailability of the DNA methyltransferase inhibitor 5-fluoro-2'-deoxycytidine in mice. Clin Cancer Res 12(24):74837491. https://doi.org/10.1158/1078-0432.CCR-06-1250

13. Holleran JL, Beumer JH, McCormick DL, Johnson WD, Newman EM et al (2015) Oral and intravenous pharmacokinetics of 5-fluoro-2'-deoxycytidine and THU in cynomolgus monkeys and humans. Cancer Chemother Pharmacol 76(4):803-811. https:// doi.org/10.1007/s00280-015-2857-x

14. Mekras JA, Boothman DA, Perez LM, Greer S (1984) Use of 5-fluorodeoxycytidine and tetrahydrouridine to exploit high levels of deoxycytidylate deaminase in tumors to achieve DNA- and target-directed therapies. Cancer Res 44(6):2551-2560

15. Newman EM, Morgan RJ, Kummar S, Beumer JH, Blanchard MS et al (2015) A phase I, pharmacokinetic, and pharmacodynamic evaluation of the DNA methyltransferase inhibitor 5-fluoro-2'-deoxycytidine, administered with tetrahydrouridine. Cancer Chemother Pharmacol 75(3):537-546. https://doi.org/10.1007/s0028 0-014-2674-7

16. Stearns V, Zhou Q, Davidson NE (2007) Epigenetic regulation as a new target for breast cancer therapy. Cancer Invest 25(8):659-665. https://doi.org/10.1080/07357900701719234

17. Pouliot MC, Labrie Y, Diorio C, Durocher F (2015) The role of methylation in breast cancer susceptibility and treatment. Anticancer Res 35(9):4569-4574

18. Maruya S, Issa JP, Weber RS, Rosenthal DI, Haviland JC et al (2004) Differential methylation status of tumor-associated genes in head and neck squamous carcinoma: incidence and potential implications. Clin Cancer Res 10(11):3825-3830. https://doi. org/10.1158/1078-0432.Ccr-03-0370

19. Bennett KL, Karpenko M, Lin MT, Claus R, Arab K et al (2008) Frequently methylated tumor suppressor genes in head and neck squamous cell carcinoma. Cancer Res 68(12):4494-4499. https ://doi.org/10.1158/0008-5472.Can-07-6509

20. Seng TJ, Currey N, Cooper WA, Lee CS, Chan C et al (2008) DLEC1 and MLH1 promoter methylation are associated with poor prognosis in non-small cell lung carcinoma. Br J Cancer 99(2):375-382. https://doi.org/10.1038/sj.bjc.6604452

21. Tada Y, Wada M, Taguchi K, Mochida Y, Kinugawa N et al (2002) The association of death-associated protein kinase hypermethylation with early recurrence in superficial bladder cancers. Cancer Res 62(14):4048-4053

22. Marsit CJ, Houseman EA, Christensen BC, Eddy K, Bueno R et al (2006) Examination of a $\mathrm{CpG}$ island methylator phenotype and implications of methylation profiles in solid tumors. Cancer Res 66(21):10621-10629. https://doi.org/10.1158/0008-5472. Can-06-1687

23. Wang L, Balasubramanian P, Chen AP, Kummar S, Evrard YA et al (2016) Promise and limits of the cell search platform for evaluating pharmacodynamics in circulating tumor cells. Semin Oncol 43(4):464-475. https://doi.org/10.1053/j.seminoncol .2016 .06 .004

24. Milano A, Mazzetta F, Valente S, Ranieri D, Leone L et al (2018) Molecular detection of EMT markers in circulating tumor cells from metastatic non-small cell lung cancer patients: potential role in clinical practice. Anal Cell Pathol (Amst) 2018:3506874. https ://doi.org/10.1155/2018/3506874

25. Qi LN, Xiang BD, Wu FX, Ye JZ, Zhong JH et al (2018) Circulating tumor cells undergoing EMT provide a metric for diagnosis and prognosis of patients with hepatocellular carcinoma. Cancer Res 78(16):4731-4744. https://doi.org/10.1158/0008-5472. Can-17-2459

26. Satelli A, Mitra A, Brownlee Z, Xia X, Bellister S et al (2015) Epithelial-mesenchymal transitioned circulating tumor cells capture for detecting tumor progression. Clin Cancer Res 21(4):899906. https://doi.org/10.1158/1078-0432.Ccr-14-0894

27. Wu S, Liu S, Liu Z, Huang J, Pu X et al (2015) Classification of circulating tumor cells by epithelial-mesenchymal transition 
markers. PLoS ONE 10(4):e0123976. https://doi.org/10.1371/ journal.pone.0123976

28. Eisenhauer EA, Therasse P, Bogaerts J, Schwartz LH, Sargent D et al (2009) New response evaluation criteria in solid tumours: revised RECIST guideline (version 1.1). Eur J Cancer 45(2):228247. https://doi.org/10.1016/j.ejca.2008.10.026

29. Karsten U, Serttas N, Paulsen H, Danielczyk A, Goletz S (2004) Binding patterns of DTR-specific antibodies reveal a glycosylation-conditioned tumor-specific epitope of the epithelial mucin (MUC1). Glycobiology 14(8):681-692. https://doi.org/10.1093/ glycob/cwh090

30. Petrakou E, Murray A, Price MR (1998) Epitope mapping of antiMUC1 mucin protein core monoclonal antibodies. Tumour Biol 19(Suppl 1):21-29. https://doi.org/10.1159/000056501

31. Allard WJ, Matera J, Miller MC, Repollet M, Connelly MC et al (2004) Tumor cells circulate in the peripheral blood of all major carcinomas but not in healthy subjects or patients with nonmalignant diseases. Clin Cancer Res 10(20):6897-6904. https://doi. org/10.1158/1078-0432.CCR-04-0378

32. de Bono JS, Scher HI, Montgomery RB, Parker C, Miller MC et al (2008) Circulating tumor cells predict survival benefit from treatment in metastatic castration-resistant prostate cancer. Clin Cancer Res 14(19):6302-6309. https://doi.org/10.1158/10780432.CCR-08-0872

33. Cristofanilli M, Budd GT, Ellis MJ, Stopeck A, Matera J et al (2004) Circulating tumor cells, disease progression, and survival in metastatic breast cancer. N Engl J Med 351(8):781-791. https ://doi.org/10.1056/NEJMoa040766

34. Olmos D, Baird RD, Yap TA, Massard C, Pope L et al (2011) Baseline circulating tumor cell counts significantly enhance a prognostic score for patients participating in phase I oncology trials. Clin Cancer Res 17(15):5188-5196. https://doi. org/10.1158/1078-0432.Ccr-10-3019

35. Munzone E, Botteri E, Sandri MT, Esposito A, Adamoli L et al (2012) Prognostic value of circulating tumor cells according to immunohistochemically defined molecular subtypes in advanced breast cancer. Clin Breast Cancer 12(5):340-346. https://doi. org/10.1016/j.clbc.2012.07.001

36. Yang JD, Campion MB, Liu MC, Chaiteerakij R, Giama NH et al (2016) Circulating tumor cells are associated with poor overall survival in patients with cholangiocarcinoma. Hepatology 63(1):148-158. https://doi.org/10.1002/hep.27944

37. Resel Folkersma L, San Jose Manso L, Galante Romo I, Moreno Sierra J, Olivier Gomez C (2012) Prognostic significance of circulating tumor cell count in patients with metastatic hormonesensitive prostate cancer. Urology 80(6):1328-1332. https://doi. org/10.1016/j.urology.2012.09.001

38. Wang LH, Pfister TD, Parchment RE, Kummar S, Rubinstein L et al (2010) Monitoring drug-induced $\mathrm{gH} 2 \mathrm{AX}$ as a pharmacodynamic biomarker in individual circulating tumor cells. Clin Cancer Res 16(3):1073-1084. https://doi.org/10.1158/1078-0432. CCR-09-2799

39. Steel GG, Lamerton LF (1966) The growth rate of human tumours. Br J Cancer 20(1):74-86. https://doi.org/10.1038/bjc.1966.9

40. Otterson GA, Khleif SN, Chen W, Coxon AB, Kaye FJ (1995) CDKN2 gene silencing in lung cancer by DNA hypermethylation and kinetics of p16INK4 protein induction by 5-aza 2'deoxycytidine. Oncogene 11(6):1211-1216

41. Kobayashi K, Hisamatsu K, Suzui N, Hara A, Tomita H et al (2018) A review of HPV-related head and neck cancer. J Clin Med 7(9):241. https://doi.org/10.3390/jcm7090241

42. Shibue T, Weinberg RA (2017) EMT, CSCs, and drug resistance: the mechanistic link and clinical implications. Nat Rev Clin Oncol 14(10):611-629. https://doi.org/10.1038/nrclinonc.2017.44

43. Aktas B, Kasimir-Bauer S, Heubner M, Kimmig R, Wimberger P (2011) Molecular profiling and prognostic relevance of circulating tumor cells in the blood of ovarian cancer patients at primary diagnosis and after platinum-based chemotherapy. Int J Gynecol Cancer 21(5):822-830. https://doi.org/10.1097/IGC.0b013e3182 $16 \mathrm{cb} 91$

44. Ghazani AA, Castro CM, Gorbatov R, Lee H, Weissleder R (2012) Sensitive and direct detection of circulating tumor cells by multimarker micro-nuclear magnetic resonance. Neoplasia 14(5):388-395. https://doi.org/10.1596/neo.12696

45. Zhang X, Li H, Yu X, Li S, Lei Z et al (2018) Analysis of circulating tumor cells in ovarian cancer and their clinical value as a biomarker. Cell Physiol Biochem 48(5):1983-1994. https://doi. org/10.1159/000492521

46. O'Sullivan Coyne G, Chen AP, Kummar S, Meehan RS, Collins J et al (2016) Phase I trial of oral 5-fluoro-2'-deoxycytidine with oral tetrahydrouridine in patients with advanced solid tumors. Eur J Cancer 69:S90. https://doi.org/10.1016/S0959-8049(16)32864-7

47. Fang F, Turcan S, Rimner A, Kaufman A, Giri D et al (2011) Breast cancer methylomes establish an epigenomic foundation for metastasis. Sci Transl Med 3(75):75ra25. https://doi.org/10.1126/ scitranslmed.3001875

48. Stefansson OA, Moran S, Gomez A, Sayols S, Arribas-Jorba C et al (2015) A DNA methylation-based definition of biologically distinct breast cancer subtypes. Mol Oncol 9(3):555-568. https:// doi.org/10.1016/j.molonc.2014.10.012

49. Pare R, Shin JS, Lee CS (2016) Increased expression of senescence markers p14(ARF) and p16(INK4a) in breast cancer is associated with an increased risk of disease recurrence and poor survival outcome. Histopathology 69(3):479-491. https://doi. org/10.1111/his.12948

50. Lebok P, Roming M, Kluth M, Koop C, Ozden C et al (2016) p16 overexpression and $9 \mathrm{p} 21$ deletion are linked to unfavorable tumor phenotype in breast cancer. Oncotarget 7(49):81322-81331. https ://doi.org/10.18632/oncotarget.13227

51. Degli Esposti D, Sklias A, Lima SC, la Forest B-d, Divonne S, Cahais V et al (2017) Unique DNA methylation signature in HPVpositive head and neck squamous cell carcinomas. Genome Med 9(1):33-33. https://doi.org/10.1186/s13073-017-0419-z

52. Hawes SE, Stern JE, Feng Q, Wiens LW, Rasey JS et al (2010) DNA hypermethylation of tumors from non-small cell lung cancer (NSCLC) patients is associated with gender and histologic type. Lung Cancer 69(2):172-179. https://doi.org/10.1016/j.lungc an.2009.11.002

53. Kaifi JT, Kunkel M, Dicker DT, Joude J, Allen JE et al (2015) Circulating tumor cell levels are elevated in colorectal cancer patients with high tumor burden in the liver. Cancer Biol Ther 16(5):690-698. https://doi.org/10.1080/15384047.2015.1026508

54. Le UT, Bronsert P, Picardo F, Riethdorf S, Haager B et al (2018) Intraoperative detection of circulating tumor cells in pulmonary venous blood during metastasectomy for colorectal lung metastases. Sci Rep 8(1):8751. https://doi.org/10.1038/s41598-018-26410 $-8$

55. Fan H, Lu X, Wang X, Liu Y, Guo B et al (2014) Low-dose decitabine-based chemoimmunotherapy for patients with refractory advanced solid tumors: a phase I/II report. J Immunol Res 2014:371087. https://doi.org/10.1155/2014/371087

56. Linnekamp JF, Butter R, Spijker R, Medema JP, van Laarhoven HWM (2017) Clinical and biological effects of demethylating agents on solid tumours - a systematic review. Cancer Treat Rev 54:10-23. https://doi.org/10.1016/j.ctrv.2017.01.004

Publisher's Note Springer Nature remains neutral with regard to jurisdictional claims in published maps and institutional affiliations. 


\section{Affiliations}

Geraldine O.'Sullivan Coyne ${ }^{1}$. Lihua Wang ${ }^{2}$. Jennifer Zlott ${ }^{1}$. Lamin Juwara ${ }^{3}$. Joseph M. Covey ${ }^{1}$. Jan H. Beumer ${ }^{4}$. Mihaela C. Cristea ${ }^{5}$. Edward M. Newman ${ }^{5}$. Stephen Koehler ${ }^{6}$. Jorge J. Nieva ${ }^{7}$. Agustin A. Garcia ${ }^{7,10}$.

David R. Gandara ${ }^{8} \cdot$ Brandon Miller $^{2}$ - Sonny Khin ${ }^{2} \cdot$ Sarah B. Miller ${ }^{1}$ - Seth M. Steinberg ${ }^{9} \cdot$ Larry Rubinstein $^{1}$. Ralph E. Parchment ${ }^{2} \cdot$ Robert J. Kinders $^{2} \cdot$ Richard L. Piekarz $^{1} \cdot$ Shivaani Kummar ${ }^{1}$. Alice P. Chen ${ }^{1}$. James H. Doroshow ${ }^{1,9}$

1 Division of Cancer Treatment and Diagnosis, National Cancer Institute, 31 Center Drive, Bldg. 31 Room 3A-44, Bethesda, MD 20892, USA

2 Clinical Pharmacodynamic Biomarkers Program, Applied/Developmental Research Directorate, Frederick National Laboratory for Cancer Research, Frederick, MD, USA

3 Clinical Monitoring Research Program, Clinical Research Directorate, Frederick National Laboratory for Cancer Research, Frederick, MD, USA

4 Department of Pharmaceutical Sciences, University of Pittsburgh School of Pharmacy, Pittsburgh, PA, USA
5 Department of Medical Oncology and Therapeutics Research, City of Hope National Medical Center, Duarte, CA, USA

6 City of Hope Medical Group, South Pasadena, CA, USA

7 University of Southern California Norris Comprehensive Cancer Center, Los Angeles, CA, USA

8 University of California Davis Cancer Center, Sacramento, CA, USA

9 Center for Cancer Research, National Cancer Institute, Bethesda, MD, USA

10 Present Address: Louisiana State University, New Orleans, LA 70112, USA 